\title{
Excretion of Toxoplasma gondii oocysts from Feral Cats in Korea
}

\author{
Kyu-Sung Ahn', Ah-Jin Ahn², Sang-ik Park', Woon-Mok Sohn", Jae-han Shim ${ }^{5, *}$, Sung-Shik Shin ${ }^{1, *}$ \\ ${ }^{1}$ Department of Parasitology, College of Veterinary Medicine, Chonnam National University, Gwangju 61186, Korea; 'wangju Metropolitan City \\ Institute Health \& Environment, Gwangju 61027, Korea; ${ }^{3}$ Department of Parasitology, College of Veterinary Medicine, Chonnam National University, \\ Gwangju 61186 Korea; ${ }^{4}$ Department of Parasitology and Tropical Medicine, and Institute of Health Sciences, Gyeongsang National University \\ School of Medicine, Jinju 52727, Korea ${ }^{5}$ Natural Products Chemistry Laboratory, College of Agriculture and Life Sciences, Chonnam National \\ University, Gwangju 61186, Korea
}

\begin{abstract}
Sporulated oocysts from the feces of infected cats with Toxoplasma gondii can cause detrimental disease in both humans and animals. To investigate the prevalence of feral cats that excrete T. gondii oocysts in the feces, we examined fecal samples of 563 feral cats over a 3-year period from 2009 to 2011 . Oocysts of $T$. gondii excreted into the feces were found from 4 of 128 cats in 2009 (3.1\%) and one of $228(0.4 \%)$ in 2010 while none of the 207 cats in 2010 were found positive with oocysts in their feces, resulting in an overall prevalence rate of $0.89 \%(5 / 563)$ between 2009 and 2011. Among the 5 cats that tested positive with T. gondii oocysts, 4 of the cats were male and 1 was a female with an average body weight of $0.87 \mathrm{~kg}$. Numerous tissue cysts of $60 \mu \mathrm{m}$ in diameter with thin $(<0.5 \mu \mathrm{m})$ cyst walls were found in the brain of one of the 5 cats on necropsy 2 months after the identification of oocysts in the feces. A PCR amplification of the T. gondii-like oocysts in the feces of the positive cats using the primer pairs Tox-5/Tox-8 and Hham34F/Hham3R confirmed the presence of $T$. gondii oocysts in the feces. This study provides a good indication of the risk assessment of feral cats in the transmission of T. gondii to humans in Korea.
\end{abstract}

Key words: Toxoplasma gondii, cat, fecal oocyst, prevalence, Korea

\section{INTRODUCTION}

Toxoplasma gondii is an obligate intracellular protozoan parasite for which almost all warm-blooded vertebrates including mammals and birds can serve as the intermediate host. The disease caused by T. gondii can be detrimental to both humans and animals [1-4]. Although multitudinous animals and humans can serve as the intermediate host, oocysts of T. gondii are excreted only from felidae. Infections in healthy adult humans are usually asymptomatic or mild. However, cervical or occipital lymphadenopathy and ocular toxoplasmosis have occurred in some patients $[5,6]$. More severe sequelae can occur if the primary infection is acquired during pregnancy in which the fetus can be severely affected resulting in hydrocephalus, retinochoroiditis, convulsions and intracerebral cal-

- Received 7 September 2019, revised 9 November 2019, accepted 19 November 2019.

*Corresponding authors (jhshim@jnu.ac.kr; sungshik@jnu.ac.kr)

(c) 2019, Korean Society for Parasitology and Tropical Medicine

This is an Open Access article distributed under the terms of the Creative Commons Attribution Non-Commercial License (http://creativecommons.org/licenses/by-nc/4.0) which permits unrestricted non-commercial use, distribution, and reproduction in any medium, provided the original work is properly cited. cification $[7,8]$. In addition to the congenital transmission route via the placenta, humans also become infected with $T$. gondii by the ingestion of insufficiently or undercooked meat containing tissue cysts or by accidental ingestion of oocysts in water or food that have been contaminated by the cat feces $[2,7,9]$.

Seroprevalence is a good risk assessment for the exposure of cats to T. gondii. There have been several studies in Korea on the prevalence of feral cats which indicated that $20.7 \%$ of cats were seropositive by the Latex agglutination [10], 8.1\% by the latex agglutination test, 16\% by ELISA, 13.2\% by PCR analysis [11], $15.8 \%$ by ELISA and $17.5 \%$ by PCR [12]. Results of these studies indicate that the infection rate of feral cats in Korea is considerably lower than cats from other countries including the United Sates where antibodies to T. gondii were found in $31 \%$ of 12,628 cats [13]. Dubey and Jones also summarized 8 seroprevalence studies of $T$. gondii in domestic cats from the USA in which $55.8 \%$ of 1,133 cats in the surveys were seropositive to T. gondii [14]. Seropositive cats to T. gondii, however, do not usually impose a threat to human transmission of the pathogen because most cats only shed oocysts for about 1 
week in their life, and seropositive cats to T. gondii had excreted oocysts into the feces prior to the development of specific antibodies, and are in general considered to be immune to reshedding of oocysts $[7,15]$. Although reshedding of oocysts can occur in some situations such as in immunocompromized patients, it is therefore a fair assumption that cats that are seropositive have already shed $T$. gondii oocysts $[9,14]$. Since oocyst-transmitted infections may be more severe than tissue cyst-induced infections [16] and cats may excrete millions of oocysts after ingesting only 1 bradyzoite or 1 tissue cyst to contaminate the living environment [17], it is still important to correctly assess the prevalence of T. gondii oocyst shedding in a population of cats. Under laboratory conditions, cats can shed as many as 500 million oocysts after ingesting 1 T. gondii-infected mouse [18].

The prevalence rate of feral cats shedding T. gondii oocysts has been reported in USA [19], Spain [20], Italy [21], and Japan [22] as $1.8 \%, 0.6 \%, 0.4 \%$, and $0.8 \%$, respectively. However, no studies have been performed to investigate the prevalence of cats shedding oocysts of T. gondii in Korea. In this study, we examined fecal samples of 563 feral cats over a 3-year period to identify cats with T. gondii oocysts in Korea. We excluded in-house pet cats in the survey because a previous report indicated that seropositivity to $T$. gondii is minimal in such population [23]. We provided molecular evidence that the oocysts excreted into cats were of T. gondii by PCR, and also identified the tissue cyst of $T$. gondii from the brain of an infected cat.

\section{MATERIALS AND METHODS}

\section{Animals}

Five hundred and sixty-three feral cats (Felis catus) of Korean shorthair were subjects of the study. Part of this study was a collateral research program supported by the Communicable Diseases Control Program of National Institute of Health (NIH), Korea Centers for Disease Control and Prevention (KCDCP). The cats were trapped from 3 different programs during a period of 3 years. In 2009, a total of 128 feral cats (75 males and 53 females, av. $1.2 \mathrm{~kg}$ b.w.) were captured in Gwangju Metropolitan City. In 2010, 207 feral cats, 91 males and 116 females with an average weight of $3.1 \mathrm{~kg}$, were captured in the Seomjin River basin areas that included Hadonggun, Gokseong-gun, Gurye-gun, Gwangyang-si, Suncheon-si, Yeosu-si and Namwon-si. Finally, in 2011, 228 feral cats, 107 male and 121 females with an average weight of $3.5 \mathrm{~kg}$ were captured from the 4 major river basin areas of Hangang, Geumgang, Yeongsangang and Nakdonggang. A humane trap designed to contain a cat without injuring or killing was used to capture feral cats. Each trap was made with a plastic cage $(25 \times 25 \times 60 \mathrm{~cm})$ with the door held open by means of a thread that was connected to a piece of fried chicken which was placed inside the trap to lure a cat. When a cat grabs and/ or bites the food, the door drops down behind the animal, enclosing the animal inside.

\section{Microscopic examinations}

Fecal samples of each feral cat were examined by the conventional Sheather's sugar flotation method using a saturated sugar solution [24]. Floated material was transferred to a slide and observed under a light microscope with a micrometer (Axioscope, Zeiss, Jena, Germany). Identification of oocysts was made by the morphological characteristics as reported previously [25].

\section{Histological examinations}

One of oocyst-excreting cats was euthanized after 2 months of captive state and necropsy was performed. Euthanasia was induced by intramuscular injection with suxamethonium chloride (1 ml/kg, Succicholine ${ }^{\circledR}$, Ilsung Paarmaceuticals, Korea) followed by an IM injection of tiletamina and zolazcepan $\left(0.05 \mathrm{ml} / \mathrm{kg}\right.$, Zoletil 50® ${ }^{\circledR}$, Virbac S.A, Carros, France). From the euthanatized cat, the entire brain was extracted, and transverse sections were made at 0.5 -cm intervals. Tissues were embedded in paraffin and sections were cut at 5-pm thickness and routinely stained with hematoxylin and eosin (HE).

PCR

Differential diagnosis between T. gondii and Hammondia hammondi oocysts was performed by PCR as previously described [8]. The oocysts of T. gondii were collected from feces, sporulated for 5 days at $24^{\circ} \mathrm{C}$ and 3 cycles of freezing $\left(-80^{\circ} \mathrm{C}\right)$ thawing were done. The pellet was subjected first to proteinase $\mathrm{K}$ digestion $\left(1 \mathrm{hr}\right.$ at $\left.60^{\circ} \mathrm{C}\right)$ and then to DNA extraction with MasterPure $^{\mathrm{TM}}$ DNA purification kit (Epicentre ${ }^{\circledR}$ Biotechnologies, USA) as specified by the manufacturer.

PCR reaction of $T$. gondii DNA in oocysts was performed in total volume of $20 \mu$ l genomic DNA, 1 unit HiPi ${ }^{\mathrm{TM}}$ thermostable DNA polymerase in $250 \mathrm{Mm}$ Tris- $\mathrm{HCl}$ (pH9.0), $80 \mathrm{Mm}$ $\left(\mathrm{NH}_{4}\right)_{2} \mathrm{SO}, 10 \%$ DMSO, $8.75 \mathrm{Mm} \mathrm{MgCl}, 0.05 \%$ bromophenol 
phenol blue, $12 \%$ glycerol and stabilizer primers pairs Tox-5/ Tox-8 (5'-CCC AGC TGC GTC TGT CGG GAT-3'/5'-GAC GTC TGT GTC ACG TAG ACC TAA G-3') and Hham34F/Hham3R (5'- ATC CCA TTC CGG CTT CAG TCT TTC-3' $/ 5^{\prime}$-ACA GCG GAG CCG AAG TTG GTT T-3') [8,26]. DNA amplification with primer pairs Tox-5/Tox-8 was conducted using the Palm Cycler (Corbett Research, Australia) in the following conditions: initial denaturation at $94^{\circ} \mathrm{C}$ for $2 \mathrm{~min}$; denaturation at $94^{\circ} \mathrm{C}$; annealing at $60^{\circ} \mathrm{C}$; extension at $72^{\circ} \mathrm{C}$ for $1 \mathrm{~min}$ for 35 cycles; and final extension at $72^{\circ} \mathrm{C}$ for $10 \mathrm{~min}$. Comparison of T. gondii with $H$. hammondii, DNA amplification using primer pairs Hham34F/Hham3R was performed under the following conditions: initial denaturation at $94^{\circ} \mathrm{C}$ for $5 \mathrm{~min}$; denaturation at $94^{\circ} \mathrm{C}$ and annealing at $60^{\circ} \mathrm{C}$ and extension at $72^{\circ} \mathrm{C}$ for $1 \mathrm{~min}$ for 35 cycles; and a final extension at $72^{\circ} \mathrm{C}$ for $10 \mathrm{~min}$. Agarose gel electrophoresis was carried out, followed by staining with ethidium bromide.

\section{RESULTS}

Results of fecal examination by the Sheather's sugar flotation of 563 feral cats are summarized in Table 1. Oocysts of $T$. gondii excreted into feces were spherical in shape and measured an average of $10 \times 12 \mu \mathrm{m}$ in diameter in the feces (Fig. 1), and were found from 4 of 128 cats in 2009 (3.1\%) and one of $228(0.4 \%)$ in 2010 while none of the 207 cats in 2010 were found positive in their feces, resulting in an overall prevalence of $0.89 \%$ (5/563) between 2009 and 2011. Among the 5 cats

Table 1. Excretion of T. gondii oocysts from feral cats trapped from 2009 to 2011 in Korea

\begin{tabular}{|c|c|c|c|c|c|c|c|c|c|c|c|c|c|c|c|c|}
\hline \multirow[b]{2}{*}{ Category } & \multicolumn{4}{|c|}{2009} & \multicolumn{4}{|c|}{2010} & \multicolumn{4}{|c|}{2011} & \multicolumn{4}{|c|}{ Total } \\
\hline & $\mathrm{Tg}+$ & Tg- & Total & $\begin{array}{c}\text { Infected } \\
(\%)\end{array}$ & $\operatorname{Tg}+$ & Tg- & Total & $\begin{array}{c}\text { Infected } \\
(\%)\end{array}$ & $\mathrm{Tg}+$ & $\mathrm{Tg}-$ & Total & $\begin{array}{c}\text { Infected } \\
(\%)\end{array}$ & $\mathrm{Tg}+$ & Tg- & Total & $\begin{array}{c}\text { Infected } \\
(\%)\end{array}$ \\
\hline \multicolumn{17}{|l|}{ Weight } \\
\hline$<1.5 \mathrm{~kg}$ & 4 & 93 & 97 & 4.3 & 0 & 4 & 4 & 0 & 1 & 3 & 4 & 33.3 & 5 & 100 & 105 & 5.0 \\
\hline$\geq 1.5 \mathrm{~kg}$ & 0 & 31 & 31 & 0.0 & 0 & 203 & 203 & 0 & 0 & 224 & 224 & 0.0 & 0 & 458 & 458 & 0.0 \\
\hline Total & 4 & 124 & 128 & 3.2 & 0 & 207 & 207 & 0 & 1 & 227 & 228 & 0.4 & 5 & 558 & 563 & 0.9 \\
\hline \multicolumn{17}{|l|}{ Gender } \\
\hline Male & 3 & 72 & 75 & 4.2 & 0 & 116 & 116 & 0 & 1 & 106 & 107 & 0.9 & 4 & 294 & 298 & 1.4 \\
\hline Female & 1 & 52 & 53 & 1.9 & 0 & 91 & 91 & 0 & 0 & 121 & 121 & 0.0 & 1 & 264 & 265 & 0.4 \\
\hline Total & 4 & 124 & 128 & 3.2 & 0 & 207 & 207 & 0 & 1 & 227 & 228 & 0.4 & 5 & 558 & 563 & 0.89 \\
\hline
\end{tabular}

Tg+: excretion of $T$. gondii oocysts, Tg-: no excretion of $T$. gondii oocysts.

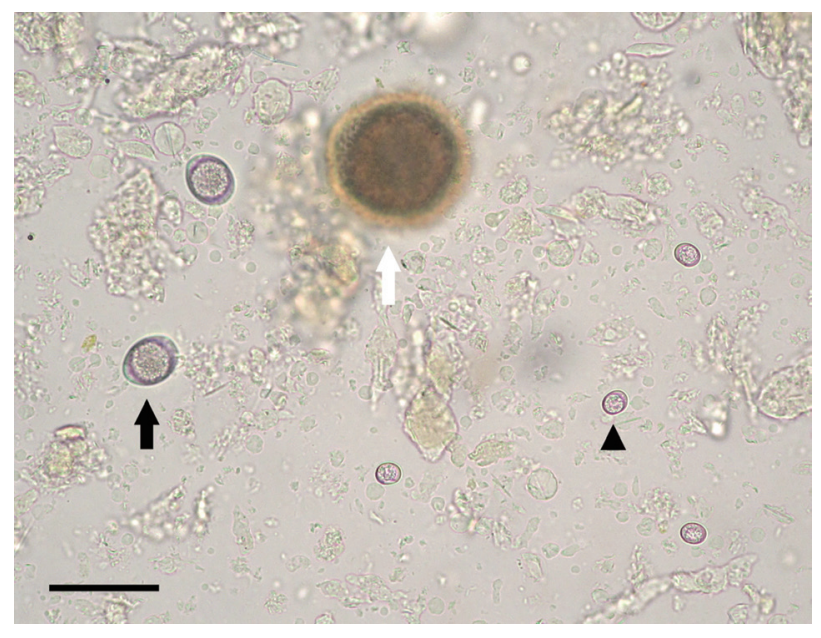

Fig. 1. Microscopic examination of feral cat feces following the Sheather's sugar flotation technique. Arrowheads: Unsporulated oocyst of Toxoplasma gondii; black arrow: unsporulated oocyst of Cystoisospora felis; white arrow: off-focused Toxocara cati egg. Bar $=50 \mu \mathrm{m}$.

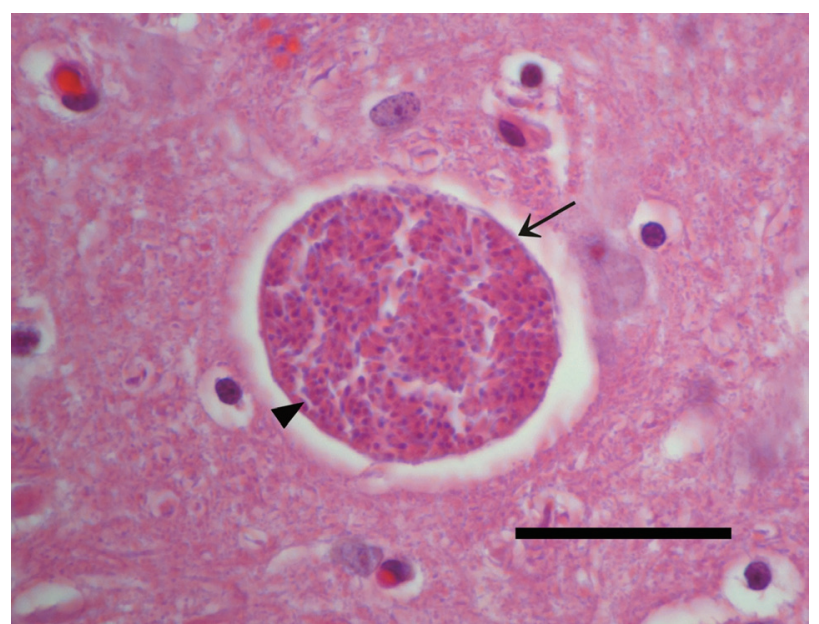

Fig. 2. Histosection of the brain tissue from a feral cat infected with Toxoplasma gondii stained with H\&E stain. Arrow: Tissue cyst wall; arrowhead: hundreds of bradyzoites. Bar $=40 \mu \mathrm{m}$. 


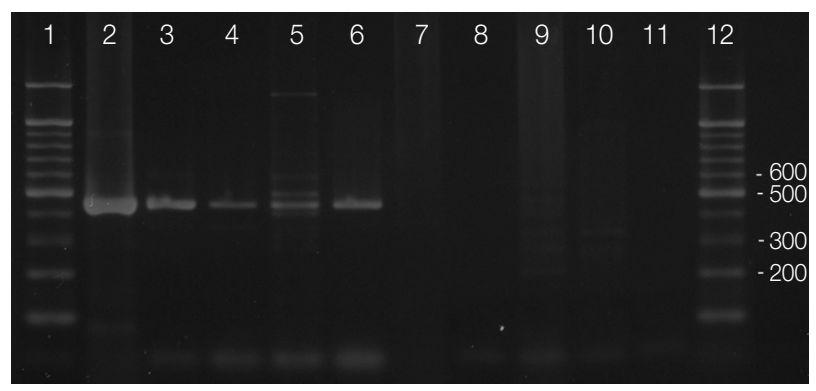

Fig. 3. Differential diagnosis of Toxoplasma gondii oocysts from Hammondia hammondi in the feces of feral cats by PCR. T. gondii-specific PCR (primer pair Tox5-Tox-8; lanes 2-6) and the $H$. hammondi-specific PCR (primer pair Hham34F-Hham3R; lanes 7-11). Genomic DNA sample of T. gondii (lane 5 and 10) was used as positive controls. Markers represent a 100-bp ladder (lane 1 and 12).

positive with T. gondii oocysts, 4 of the cats were male and 1 was female with an average body weight of $0.87 \mathrm{~kg}$. Four cats were co-infected with Toxocara cati and 3 with Cystoisospora felis. In the feces of the cat caught in 2011, numerous oocysts were observed which number was estimated as $1.82 \times 10^{6} / \mathrm{g}$ of feces.

Tissue cysts were found in the brain of one of the 5 cats after 2 months upon necropsy. The tissue cyst wall was thin $(<0.5$ $\mu \mathrm{m})$ and hundreds of crescent-shaped bradyzoites with a nucleus situated toward the posterior end were observed (Fig. 2). The size of tissue cysts was approximately $60 \mu \mathrm{m}$ in diameter.

Primer pair Tox-5/Tox-8 and Hham34F/Hham3R used in PCR amplification of cat feces containing T. gondii-like oocysts confirmed the presence of T. gondii oocysts in the feces (Fig. 3). Amplified products of the expected sizes were formed in line 2-6 by using primer Tox-5/Tox-8, but no amplification was observed line 7-11 by using primer Hham34F/Hham3R as the same samples (Fig. 3). All samples of oocysts from the feces of the 5 cats were identified as the oocysts of T. gondii.

\section{DISCUSSION}

This study investigated 563 feral cats of Korean short hair between January 2009 and December 2011 which were trapped from 5 major river basin areas in Korea and we discovered the 5 young cats $(0.89 \%)$ with an average body weight of $0.87 \mathrm{~kg}$ were excreting T. gondii oocysts in the feces. Since infective oocyst is the only practical threat to human transmission in association with cats, this study provides a good indication of the risk assessment of feral cats in the transmission of $T$. gondii to humans in Korea.
Although this is the first report in Korea on the prevalence of cats shedding $T$. gondii oocysts, such studies have been reported from other countries $[19,21,27]$. For example, the rate of $T$. gondii oocyst excretion in feral cats reported from USA $[19,28,29]$, Spain [20], Italy [21], Japan [22], and Brazil [30] was $0.7 \%, 1.8 \%, 0.6 \%, 0.4 \%, 0.8 \%$, and $0.5 \%$, respectively. Our result also was determined to be at a similar ratio to those of previous reports.

Discrepancies have existed between seroprevalence rates of feline toxoplasmosis and those of oocyst production in a population because cats infected with $T$. gondii excrete oocysts into feces only for 1 to 3 weeks after a short 10-day of prepatent period [3]. After the first infection, cats develop tissue cysts in the muscle, nervous system and other organs, and are considered to be immune to reshedding of oocysts for the rest of their lifetime. For this reason, results of this study was contrary to the previous surveys on the seroprevalences of $T$. gondii in feral or stray cat populations in Korea which were $20.7 \%$ by LAT [10]; $8.1 \%$ by LAT, $16 \%$ and $13.2 \%$ by ELISA and PCR analysis [11] and $15.8 \%$ and $17.5 \%$ by ELISA and PCR [12].

Although the percent of cats expected to shed oocysts at any given time is approximately $1 \%[7,15]$, it could be even more difficult to find oocyst-shedding cats among household cats if they are not allowed to hunt mice and rats. The difference in seroprevalence rates between feral and household cats in a population supports this assumption. For instance, seropositive rates of $T$. gondii were $15.0 \%$ in outdoor and $4.6 \%$ in household cats in Japan [31], 36.9\% in stray cats and 25.5\% in household cats in Spain [32] and 30.7\% in stray cats and $17.9 \%$ in household cats in China. In Korea, one study reported seroprevalence rate of $38.0 \%$ in stray cats while no positive cats were detected in household cats [23]. This result is quite reasonably expected because Koreans have a custom to keep their pet cats indoors. If they provide their cats with commercial dry and/or canned food and no raw meat, indoor type cats rarely have access to get infected with $T$. gondii.

Together with low prevalence of oocyst-shedding cats and the custom of keeping pet cats indoors, keeping raw meat out of cat's reach would minimize the opportunity of being infected with T. gondii via pet cats in Korea. It is assumed that cleaning the cat litter box is an important risk factor for T. gondii infection, but a case-control study in Norway to identify preventable risk factors for T. gondii infection in pregnancy indicated that eating raw or undercooked minced meat products, eating unwashed raw vegetables or fruits, eating raw or undercooked 
mutton, eating raw or undercooked pork were more associated with $T$. gondii infection in pregnancy than cleaning the cat litter box [33]. In a European multicenter study conducted in several regions of France, Italy, Belgium, Denmark and Sweden, between $30 \%$ and $63 \%$ of infections in the different centers were attributed to consumption of undercooked or cured meat products and $6 \%$ to $17 \%$ to soil contact [34]. Since ingestion of oocyst-contaminated food or water is the only practical way to get infected with $T$. gondii in association with cat, low prevalence of cats with T. gondii oocysts in the feces of cats in Korea may help reduce the fear and public perception of cats as the major source for human transmission of toxoplasmosis.

Reports indicate that seropositivity to toxoplasmosis among Korean residents is distinctively low compared to that of Europeans and Americans. According to previous surveys of humans in Korea, the seropositivities of T. gondii were 5.8\% [35], $3.8 \%$ by ILA, $7.0 \%$ by ELISA [36], $6.9 \%$ by ELISA [37], $0.88 \%$ by ELISA [38], 3.7\% by DT, 3.4\% by LAT, $4.0 \%$ by ELISA [39], $6.6 \%$ by LAT, and $6.7 \%$ by ELISA [40]. By contrast, selected serological surveys in humans in the USA summarized by Dubey and Jones showed seropositivity ranging between $10.8 \%$ and $31 \%$ from 1962 to 2004 [14]. When analyzing the seroprevalences of T. gondii infection between the 2 countries, Americans were approximately twice as high as Koreans. In Europe, serum from healthy house cats aged 3 months to 7 years revealed that $24.9 \%$ of cats in Belgium were seropositive for $T$. gondii by IIFA [1]. Stray cats in Belgium showed an even higher rate for T. gondii in that $70.2 \%$ (243/346) of serum samples taken between 1998 and 2000 from urban stray cats in the city of Ghent were positive for T. gondii [41]. In contrast, seroprevalence of T. gondii in 1,447 domestic cats from Japan was only $5.4 \%$ and no significant differences in seropositivities were observed in T. gondii infections concerning to both genders and raising status [31].

One of the reasons for the low prevalence in seropositivity to T. gondii among Koreans can be attributed to the low population of people raising cats as pets in Korea. According to a study in Korea, the population of dogs had amounted to $97.8 \%$ of the total number of cats and dogs as pets in 2006 [42]. The custom of consuming fully cooked meat by Korean residents especially with pork meat may also contribute to the low seroprevalence of toxoplasmosis among Koreans.

\section{ACKNOWLEDGMENTS}

This study was supported by the Communicable Diseases Control Program (2011E5400700: Epidemiological survey on the infection status of Clonorchis sinensis in reservoir and intermediate hosts for its management) of National Institute of Health (NIH), Korea Centers for Disease Control and Prevention (KCDCP).

\section{CONFLICT OF INTEREST}

We have no conflict of interest related to this work.

\section{REFERENCES}

1. De Craeye S, Francart A, Chabauty J, De Vriendt V, Van Gucht S, Leroux I, Jongert E. Prevalence of Toxoplasma gondii infection in Belgian house cats. Vet Parasitol 2008; 157: 128-132.

2. Dubey JP, Beattie CP. Toxoplasmosis of Animals and Man. Boca Raton, USA. CRC Press. 1988, pp. 1-232.

3. Dubey JP. Toxoplasmosis of Animals and Humans. Boca Raton, USA. CRC Press. 2010, pp 1-30.

4. Tenter AM, Heckeroth AR, Weiss LM. Toxoplasma gondii: from animals to humans. Int J Parasitol 2000; 30: 1217-1258.

5. 5Bowie WR, King AS, Werker DH, Isaac-Renton JL, Bell A, Eng $\mathrm{SB}$, Marion SA. Outbreak of toxoplasmosis associated with municipal drinking water. The BC Toxoplasma Investigation Team. Lancet 1997; 350: 173-177.

6. Burnett AJ, Shortt SG, Isaac-Renton J, King A, Werker D, Bowie WR. Multiple cases of acquired toxoplasmosis retinitis presenting in an outbreak. Ophthalmology 1998; 105: 1032-1037.

7. Dubey JP. Toxoplasmosis-a waterborne zoonosis. Vet Parasitol 2004; 126: 57-72.

8. Schares G, Herrmann DC, Beckert A, Schares S, Hosseininejad M, Pantchev N, Globokar Vrhovec M, Conraths FJ. Characterization of a repetitive DNA fragment in Hammondia hammondi and its utility for the specific differentiation of H. hammondii from Toxoplasma gondii by PCR. Mol Cell Probes 2008; 22: 244-251.

9. Hill D, Dubey JP. Toxoplasma gondii: transmission, diagnosis and prevention. Clin Microbiol Infect 2002; 8: 634-640.

10. Han DU, Lee CG, Kang MI, Hwan J, Kim SH, Kim HJ, Wee SH. Serological studies on Toxoplasma gondii, Hantavirus and some rickettsial pathogens in stray cats in Korea. Korean J Vet Pub Health 1999; 23: 301-310.

11. Kim HY, Kim YA, Kang S, Lee HS, Rhie HG, Ahn HJ, Nam HW, Lee SE. Prevalence of Toxoplasma gondii in stray cats of Gyeonggido, Korea. Korean J Parasitol 2008; 46: 199-201.

12. Lee SE, Kim NH, Chae HS, Cho SH, Nam HW, Lee WJ, Kim SH, Lee JH. Prevalence of Toxoplasma gondii Infection in Feral Cats in Seoul, Korea. J Parasitol 2011; 97: 153-155. 
13. Vollaire MR, Radecki SV, Lappin MR. Seroprevalence of Toxoplasma gondii antibodies in clinically ill cats in the United States. Am J Vet Res 2005; 66: 874-877.

14. Dubey JP, Jones J. Toxoplasma gondii infection in humans and animals in the United States. Int J Parasitol 2008; 38: 1257-1278.

15. Dubey JP. Duration of immunity to shedding of Toxoplasma gondii oocysts by cats. J Parasitol 1995; 81: 410-415.

16. Torrence ME, Isaacson RE. Microbial Food Safety in Animal Agriculture. Ames, USA. Iowa State Press. 2003, pp 359-367.

17. Dubey JP. Oocyst shedding by cats fed isolated bradyzoites and comparison of infectivity of bradyzoites of the VEG strain Toxoplasma gondii to cats and mice. J Parasitol 2001; 87: 215-219.

18. Dubey JP, Frenkel JK. Cyst-induced toxoplasmosis in cats. J Protozool 1972; 19: 155-177.

19. Dubey J, Weigel R, Siegel A, Thulliez P, Kitron U, Mitchell M, Mannelli A, Mateus-Pinilla N, Shen S, Kwok O. Sources and reservoirs of Toxoplasma gondii infection on 47 swine farms in Illinois. J Parasitol 1995: 723-729.

20. Aparicio Garrido J, Boveda IC, Aguilar AMB, Miralles JP. Estudios sobre la epidemiologia de la toxoplasmosis. La infeccion del gato domestico en los alrededores de Madrid. Encuestas serologica y coproparasitologica. Med Trop 1972; 48: 24-39.

21. Pampiglione S, Poglayen G, Arnone B, De Lalia F. Toxoplasma gondii oocysts in the faeces of naturally infected cat. Br Med J 1973; $2: 306$.

22. Ito S, Tsunoda K, Nishikawa H, Matsui T. Small type of Isospora bigemina: isolation from naturally infected cats and relations with toxoplasma oocyst. Natl Inst Anim Health Q 1974; 14: 137-144.

23. Lee SE, Kim JY, Kim YA, Cho SH, Ahn HJ, Woo HM, Lee WJ, Nam HW. Prevalence of Toxoplasma gondii infection in stray and household cats in regions of Seoul, Korea. Korean J Parasitol 2010; 48: 267-270.

24. Zajac AM, Conboy GA. Veterinary Clinical Parasitology. Chichester, UK. Wiley-Blackwell. 2012, pp 4-12.

25. Dubey JP, Miller NL, Frenkel JK. The Toxoplasma gondii oocyst from cat feces. J Exp Med 1970; 132: 636-662.

26. Reischl U, Bretagne S, Krüger D, Ernault P, Costa JM. Comparison of two DNA targets for the diagnosis of Toxoplasmosis by real-time PCR using fluorescence resonance energy transfer hybridization probes. BMC infectious diseases 2003; 3: 7.

27. Rifaat MA, Arafa MS, Sadek MS, Nasr NT, Azab ME, Mahmoud W, Khalil MS. Toxoplasma infection of stray cats in Egypt. J Trop Med 1976; 79: 67-70.

28. Wallace GD. Isolation of Toxoplasma gondii from the feces of naturally infected cats. J Infect Dis 1971; 124: 227-228.

29. Wallace GD. The role of the cat in the natural history of Toxoplasma gondii. Am J Trop Med Hyg 1973; 22: 313.
30. Nery-Guimaraes F, Lage HA. Producao irregular e inconstante de oocistos pela ministracao de cistos de "Toxoplasma gondii"Nicolle \& Manceaux, 1909, em gatos. Mem Inst Oswaldo Cruz 1973; 71: $157-170$.

31. Maruyama S, Kabeya H, Nakao R, Tanaka S, Sakai T, Xuan X, Katsube Y, Mikami T. Seroprevalence of Bartonella henselae, Toxoplasma gondii, FIV and FeLV infections in domestic cats in Japan. Microbiol Immunol 2003; 47: 147-153.

32. Miró G, Montoya A, Jiménez S, Frisuelos C, Mateo M, Fuentes I. Prevalence of antibodies to Toxoplasma gondii and intestinal parasites in stray, farm and household cats in Spain. Vet Parasitol 2004; 126: 249-255.

33. Kapperud G, Jenum PA, Stray-Pedersen B, Melby KK, Eskild A, Eng J. Risk factors for Toxoplasma gondii infection in pregnancy results of a prospective case-control study in Norway. Am J Epidemiol 1996; 144: 405-412.

34. Cook AJ, Gilbert RE, Buffolano W, Zufferey J, Petersen E, Jenum PA, Foulon W, Semprini AE, Dunn DT. Sources of toxoplasma infection in pregnant women: European multicentre case-control study. European Research Network on Congenital Toxoplasmosis. BMJ 2000; 321: 142-147.

35. Soh CT, Lee SJ, Ahn Y. Latent infection by Toxoplasma gondii in Korea. Yonsei Med J 1960; 1: 52-54.

36. Choi WY, Nam HW, Youn JH, Kim DJ, Kong Y, Kang SY, Cho SY. Detection of antibodies in serum and cerebrospinal fluid to Toxoplasma gondii by indirect latex agglutination test and enzyme-linked immunosorbent assay. Korean J Parasitol 1992; 30: 83-90.

37. Yang HJ, Jin KN, Park YK, Hong SC, Bae JM, Lee SH, Choi HS, Hwang HS, Chung YB, Lee NS. Seroprevalence of toxoplasmosis in the residents of Cheju island, Korea. Korean J Parasitol 2000; 38: 91-93.

38. Song KJ, Shin JC, Shin HJ, Nam HW. Seroprevalence of toxoplasmosis in Korean pregnant women. Korean J Parasitol 2005; 43: 69-71.

39. Han K, Shin DW, Lee TY, Lee YH. Seroprevalence of Toxoplasma gondii infection and risk factors associated with seropositivity of pregnant women in Korea. J Parasitol 2008; 94: 963-965.

40. Shin DW, Cha DY, Hua QJ, Cha GH, Lee YH. Seroprevalence of Toxoplasma gondii infection and characteristics of seropositive patients in general hospitals in Daejeon, Korea. Korean J Parasitol 2009; 47: 125-130.

41. Dorny P, Speybroeck N, Verstraete S, Baeke M, De Becker A, Berkvens D, Vercruysse J. Serological survey of Toxoplasma gondii, feline immunodeficiency virus and feline leukaemia virus in urban stray cats in Belgium. Vet Rec 2002; 151: 626-629.

42. NVRQS. A public opinion survey on animal protection in Korea. J Korean Vet Med Assoc 2007; 43: 225-236. 